Revue d'histoire de l'enfance « irrégulière »

Le Temps de l'histoire

$3 \mid 2000$

L'enfant de justice pendant la guerre et l'immédiat après-guerre

Pierre Giolitto, « Histoire de la jeunesse sous Vichy »

Paris, Perrin, 1991, 691 p.

Vincent Peyre

(2) OpenEdition

Journals

Édition électronique

URL : http://journals.openedition.org/rhei/49

DOI : $10.4000 /$ rhei. 49

ISBN : 978-2-7535-1640-3

ISSN : $1777-540 \mathrm{X}$

Éditeur

Presses universitaires de Rennes

Édition imprimée

Date de publication : 15 novembre 2000

Pagination : 275-276

ISSN : 1287-2431

Référence électronique

Vincent Peyre, "Pierre Giolitto, « Histoire de la jeunesse sous Vichy » ", Revue d'histoire de l'enfance "

irrégulière » [En ligne], 3 | 2000, mis en ligne le 15 mai 2007, consulté le 03 décembre 2020. URL

http://journals.openedition.org/rhei/49 ; DOI : https://doi.org/10.4000/rhei.49

(C) PUR 


\section{Pierre Giolitto}

Histoire de la jeunesse sous Vichy

Paris, Perrin, 1991, 691 p.

Pierre Giolitto est spécialiste de l'histoire de l'enseignement. On lui doit entre autres une Histoire de l'enseignement primaire au XIXème siècle. On ne s'étonnera donc pas de le voir consacrer une grande part de cet ouvrage à la politique scolaire et universitaire de Vichy et à la vie scolaire pendant cette période.

Foisonnant, nourri d'anecdotes, d'exemples et de portraits d'acteurs grands et petits, il nous fait pénétrer dans l'intimité du sérail vichyssois, avec ses clans, ses intrigues et ses insurmontables contradictions. Il nous montre aussi un corps enseignant rétif certes à l'idéologie cléricale et anti-républicaine officielle, objet d'ailleurs de la méfiance du nouveau pouvoir (les écoles normales d'instituteurs seront supprimées dès l'automne 1940), mais longtemps passif dans sa masse et qui ne basculera que progressivement dans une opposition et une résistance actives qui resteront le fait d'une minorité.

Il nous montre aussi une jeunesse objet de tous les soins du nouveau régime soucieux de l'engager dans la croisade pour la "révolution nationale", combat définitivement perdu en 1942 avec le collaborationnisme actif du gouvernement Laval et la mise en place du "service du travail obligatoire".

En comparaison, la place réservée au traitement de "l'enfance coupable" qui fut, on le sait, une des préoccupations du régime, ne trouve ici qu'une place modeste (deux pages) dans le chapitre consacré à " la famille, divinité nouvelle ». Par contre, l'effort considérable déployé pour enrégimenter et endoctriner une jeunesse abandonnée à elle-même au lendemain de l'exode et de la défaite - c'est ce que l'auteur appelle " la folle aventure des chantiers de jeunesse " - est fort bien décrit, de même que l'échec des tentatives d'un clan minoritaire et fascisant du régime pour créer un mouvement de jeunesse unique sur le modèle des Hitlerjungends ou des Balilas. A cette occasion est fournie une large des-

Vincent Peyre / pp. 275 à 276 
cription des rapports complexes et ambigus du régime avec les mouvements de jeunesse et leur éloignement progressif, y compris de la part du scoutisme catholique, pourtant ferme soutien du maréchalisme dans les premières années, de même que la hiérarchie de l'Eglise, à peu d'exceptions près.

Mais ce qui marque peut-être le plus les politiques de l'enseignement et de l'éducation, c'est un profond anti-intellectualisme. "La jeunesse que veut le Maréchal » est "propre de toutes les propretés physiques et morales »- il y a une obsession vichyste de la propreté -, elle est gaie, fière et virile, mais elle n'a que faire des spéculations intellectuelles et de la critique. Georges Lamirand, qui n'était pas des plus extrémistes, s'adressant aux jeunes en 1942, s'exclame : «il faut avoir la foi du charbonnier, il faut suivre le chef aveuglément. Chercher à comprendre, mais vous n'avez rien à comprendre [...]. Croire, obéir, combattre... ». Aux antipodes de la jeunesse d'avantguerre, veule, adonnée aux plaisirs, élevée dans la perversion du sens moral par des maitres aussi douteux qu'André Gide.

Parfois difficile à suivre parce que le parti pris thématique du plan oblige à des redites et à des retours, l'ouvrage vaut surtout, à notre sens, par ce qu'il nous donne à voir de la vie de Vichy et sous Vichy et de ses acteurs individuels et collectifs.

On pourra être plus réservé sur ses interprétations. C'est ainsi que le chapitre terminal, fort élogieux, sur "l'ordre des chevaliers d'Uriage ", se conclut par l'affirmation qu'Uriage (tout de même entré en dissidence dès 1942), représenterait "un pétainisme qui, par-delà ses erreurs d'appréciation conjoncturelles, se trouve porteur d'un certain nombre de valeurs universelles ", montrant par là que l'auteur éprouve malgré tout quelque sympathie pour l'idéologie vichyssoise.

Vincent Peyre 